\title{
Modern structure of the higher architectural and construction education
}

\author{
Olga Sotnikova ${ }^{1,},{ }^{*}$ Iana Zolotukhina ${ }^{1}$ and Ekaterina Prokshits ${ }^{1}$ \\ ${ }^{1}$ Voronezh State Technical University, Moscovskiy prospect, 14, Voronezh, 394026, Russia
}

\begin{abstract}
The analysis of the higher education in the sphere of sustainable development shows that there is a need to include the concept of sustainable and practical design thinking at all levels, starting from ideological level (stability as conceptual and ethical justification of architecture), methodological level (the principles and strategy for the solution of various subject matters), and finally, practical level, by introducing stability concerning programs for architectural education to impart abilities to critically analyze process and to creatively find sustainable solutions which can be developed for creation of the environment. The two-level programs implemented at the universities consisting of the system of architectural education and a subsystem of steady architectural design (consisting of the steady theoretical and design training/practical courses and cross-disciplinary courses connected with education in the field of sustainable development in the architectural training program) are presented in this article.
\end{abstract}

\section{Introduction}

Over the years, a variety of international conventions have addressed the role of higher education in the pursuit of sustainable development. Likewise, there are numerous international and regional declarations relating specifically to sustainability in curriculum. Agenda 21 is a non-binding action plan of the United Nations with regard to sustainable development. It is a product of the Earth Summit (UN Conference on Environment and Development) held in Rio de Janeiro, Brazil, in 1992. It is an action agenda for the UN, other multilateral organizations, and individual governments around the world that can be executed at local, national, and global levels [1].

The "21" in Agenda 21 refers to the 21 st century. It has been affirmed and had a few modifications at subsequent UN conferences. Its aim is achieving global sustainable development. One major objective of the agenda 21 is that every local government should draw its own local Agenda 21. Since 2015, Sustainable Development Goals are included in the Agenda 2030.

The Talloires Declaration and others like it commit signatory institutions to standards around sustainability in the curriculum. Various regional organizations provide resources and support to institutions striving for curricular change and improvement. Various regional

${ }^{*}$ Corresponding author: hundred@vgasu.vrn.ru 
organizations provide resources and support to the institutions seeking for changes and improvement of training programs.

In spite of the honorable intentions of these declarations, the number of institutions becoming signatories to them is limited. And of those that have signed on, many have failed to work towards sustainability in a meaningful way or struggled to fulfil their commitments[2].

\section{Materials and methods}

Training in the sphere of sustainable development represents a difficult task for education in all areas, it should not be considered separately, it should be considered as a unit in which several spheres of scientific and educational activity are connected. The creation of a sustainable future requires collaboration among professionals, academics and relevant stakeholders (Bell, 2005). Furthermore, Jabareen (2011) agreed to this multidisciplinary view by stating that the knowledge of sustainable development is multidisciplinary in its nature and it is covered by various bodies of sciences. They also noted that the implication of sustainable development should be studied from multidisciplinary angles, including the ecology, economics, the social sciences and technology. The reason for multidisciplinary involvement is not far- fetched - over time, seasoned professionals and stakeholders concerned with sustainability suggest that meeting the needs of the future depends on how well we find equilibrium among social, economic, and environmental objectives--or needs-when making decisions today (World Bank Institute (WBI) (2002). This is illustrated in (Figure 1).

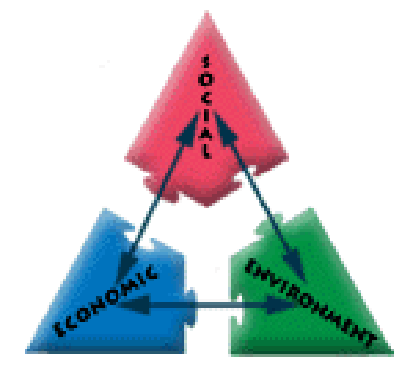

\begin{tabular}{|r|c|l|}
\hline Services & Equity & Biodiversity \\
Household Needs & Participation & Natural Resources \\
Industrial Grow th & Empowerment & Carrying Capacity \\
Agricultural Grow th & Social Mobility & Ecosystem Integrity \\
Efficient Use of Labor & Cultural Preservation & Clean Air and Water \\
\hline
\end{tabular}

Fig. 1. The trifocals of sustainable development.

Duty of the architect of the environment is creation of steady architecture in the steady environment.

The concept of sustainable development should be more prioritised at all levels of education (under-graduate and post graduate) in the Schools of Architecture in developing countries. This will strengthen the proper mentorship of environmentally-responsive architects [3]. Consequently, the sustainable impact of architectural education will be reflected in the human habitat through the design and construction of sustainable buildings.

Sustainability in social, economic or architectural concepts should be seen within the environmental purview. This is because they all operate within the environment and not outside. The model depicting their interconnectivity reduces the mother-nature of the 
environment. All disciplines should work together with nature and within the context of the environment and not outside it. This is illustrated in the model in (Figure 2).

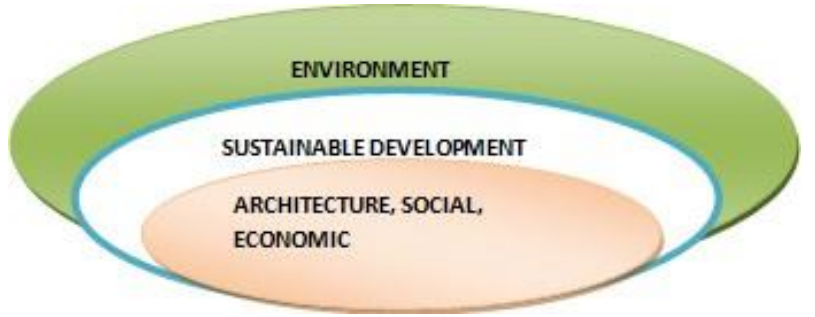

Fig. 2. A model which better describes the functional relationship among environment, sustainable development and architecture.

The need to initiate a change in architectural education that supports the implementation of considerations of sustainability in architecture is mainly triggered by the following factors: natural resource depletion, climate change, ecological damage, current building practices have been slow to respond to the need of enhancing sustainable environmental design within a creative architectural discourse; accreditation and qualification criteria established by professional bodies do not yet comprehensively contribute to the efficient promotion of environmental sustainability in building design; university curricula have proved to be sparsely effective in systematically integrating sustainable environmental design in the education of students of architecture [4].

The role of higher education in creating a more environmentally sustainable future is undeniable.

\subsection{International experience of training of specialists in the sphere of sustainable development}

California Polytechnic State University, San Luis Obispo.Those interested in an interdisciplinary approach to architecture will want to explore the Department of Architecture at California Polytechnic State University. It is one of five departments in the College of Architecture and Environmental Design (CAED). In the Master's program, students can choose to focus on Innovating Material Practice or Sustainable Architecture.

The Technische Universität München (TUM) Department of Architecture has 1.500 students in its research-oriented education. The eight-semester Bachelor's program in Architecture gives students a solid education, focusing on its core "Architectural Design", around which all the teaching and research activities occur[5]. At the master's level, students at this top architecture school can choose from several degrees: The interdisciplinary master in Energy Efficient and Sustainable Building, which focuses on graduates in architecture, civil and structural engineering, and environmental engineering.

The National University of Singapore (NUS) is one of the top architecture schools that is consistently ranked as among the top 10 world-class programs. With a strong entrepreneurial spirit and a program that is multidisciplinary and imbued with choice, the Department of architecture is known for delivering professionals that are well prepared to be global citizens as well as designers [9]. The university offers a Bachelor of Arts in Architecture, however this is not a professional program. That is the NUS Master of Architecture (M.Arch), which is recognized by Singapore Board of Architects. In Singapore, practicing architects must have completed 5 years of education plus 2 years of practical experience. In addition to the Master of Architecture, NUS also offers related 
graduate programs in Urban Design, Landscape Architcture, Integrated Sustainable Design and Urban Planning.

The undergraduate sustainability specialization at Michigan State University is based on eight competencies, four relating to content and four based on process. The latter include civic engagement, critical and systems thinking, and personal development. Seven to eight tasks guide learning in each competency area[6].

A comprehensive set of competencies plays a part in curriculum planning at Arizona State University's School of Sustainability (SOS). Basic competencies (relevant for all of the university's graduates) include critical thinking, communication, and data management. Layered on top of this for SOS students is interpersonal competence, and above this a combination of systems thinking, anticipatory, normative, and strategic competencies.[7];

In order to better integrate sustainability and utilize both imaginative and technical skills, it is necessary to reconsider architectural education by implementing creative and sustainable design methods. Most programs base their training on architectural design studios (hereafter, studios). Studios are practical courses in which students simulate a variety of design tasks that they would experience in an architectural firm. University curricula generally offer theoretical courses, which provide the necessary background and knowledge, in parallel with studios. This studio-based curriculum integrating theoretical support follows the International Union of Architects' (UIA) guidelines.

Proper integration is generally considered to be a desirable strategy involving optimal output [8]. Therefore, the value of thorough analysis and research toward improving sustainability-centric architectural education accrediting systems, not only in theory courses but also in studios, cannot be over-emphasized.

Sustainability issues related to architectural education have been evaluated over a relatively short research period. Some early studies stressed the need for sustainability in architectural education. For example, Wright introduced the way in which sustainable design could be integrated into coursework with a clear description in the curriculum [9, 10]. This curricular improvement helped connect theory and application between education and professional practice. In addition, Warburton introduced the concept of deep learning, which is crucial for sustainability education [11]. Given the range and interconnectedness of environmental, social and economic issues, as well as the importance of interdisciplinary thinking and holistic insight with respect to global environmental justice, deep learning is particularly relevant to sustainability education.

More practically, Kahn et al. pointed out a significant gap between academia and practice in architecture [12]. The authors suggested that sustainability should be taught as an intrinsic value of design, rethinking conventional notions of sustainability, ecology and energy, in order to create alternative conceptions in architectural education. This framework would be complemented by empirical and productive dialogues between architectural theory and practice.

In Europe, Altomonte et al. coordinated the Environmental Design in University Curricula and Architectural Training in Europe (EDUCATE) Project between 2009 and 2012 [13]. This was the most extensive and detailed study we found. It focused on the implementation of sustainability education in Europe after the Bologna unification process. A total of 69 programs were reviewed in terms of the degree to which sustainability was taught and practiced in architecture and urban design. The authors also offered guidelines for curriculum development in professional education [14].

Subsequently, Altomonte et al. assessed the efficacy of the EDUCATE Project in order to identify strategies to facilitate knowledge transfer between the creative and scientific disciplines at the core of sustainable architecture and urban design [15]. The paper was structured in the following three parts: the first presented the challenges in practicing sustainable design; the second elaborated on the barriers to and opportunities for promoting 
sustainability in higher education; and the third put forth a map for implementing sustainability education in architecture and urban design. Specific suggestions were summarized in three areas: integration of theory and studios (including innovative approaches as learning-by-doing and PBL); improvement of students' ethos and motivation; and implementation of more intensive use of information and communication technologies (including a wider use of e-courses).

In Asia, Shari and Jaafar analyzed nine architecture schools in Malaysia to assess how well they integrated sustainability issues into their programs [14]. They conducted a quantitative analysis of the curricula and a qualitative analysis of a survey and concluded that it would be difficult to properly implement sustainable programs using the existing curricula. Thus, the authors provided some basic recommendations to gradually transition to a more environmentally-conscious curriculum.

More widely, Álvarez et al. focused on education for sustainable architecture in Asian countries [16]. The authors compared the curricula of 20 selected schools across 11 counties, all with accredited undergraduate professional programs. Sustainability-related courses were identified, classified and compared between schools. The comparison comprised the extent to which sustainability-related content was offered, the general contents and organization of the courses throughout the programs and their integration with studios. It was concluded that the implementation of sustainability issues in the programs was inconsistent. Many of the programs dealt with environmental issues, with a focus on energy, while only a few programs included sociocultural issues. Almost all programs were deficient in addressing economic issues.

Most of the aforementioned researchers analyzed programs approved by their national accrediting boards. However, they did not address whether or not these accreditation systems supported, or hindered, the implementation of consistent sustainability education. As discussed in the 'Sustainable Architecture Education White Paper', sustainable architectural education needs full support from accreditation systems and regulatory bodies [17]. Therefore, it is unrealistic to expect real sustainable architectural education without an adequate framework for regulation that defines minimum standards.

In Table 1, the main categories of sustainable development and approximate names of courses are marked out.

Table 1. Sustainability core course categories and exemplary course names.

\begin{tabular}{|l|l|l|}
\hline $\begin{array}{l}\text { Category } \\
\text { Abbreviations }\end{array}$ & $\begin{array}{l}\text { Sustainability Core Course } \\
\text { Category }\end{array}$ & Exemplary Courses Names \\
\hline E & Environmental courses & $\begin{array}{l}\text { Principles of Architectural Environments, } \\
\text { Architectural Environment Planning, } \\
\text { Architectural Environmental Control Systems }\end{array}$ \\
\hline I & Integrated courses & $\begin{array}{l}\text { Building Systems, } \\
\text { Facade Systems, } \\
\text { Architectural Details }\end{array}$ \\
\hline MA & Material courses & Architectural Materials and Methods \\
\hline ME & $\begin{array}{l}\text { Mechanical, Electrical and } \\
\text { plumbing courses }\end{array}$ & Architectural HVAC \\
\hline SI & Site-related courses & $\begin{array}{l}\text { Site Design, } \\
\text { Landscape Architecture } \\
\text { Urban Planning and Design, Understanding } \\
\text { Cities }\end{array}$ \\
\hline
\end{tabular}

The focus of the remaining sections is on the eight sustainability SPCs. Here, the total amount of credits assigned to each of the five sustainability core course categories is evaluated to illustrate the average total credit ratio of the five course categories, in order to identify foci on specific topics and categories. The sustainability core courses at all 48 
programs account for an average of $65.9 \%$ of all credits assigned to sustainability-related courses. The relative distribution of credits amongst each of the five sustainability core course categories (Figure 3) illustrates that integration has the highest portion of credits $(25.7 \%)$, followed by environment $(22.4 \%)$, site $(18.7 \%)$, mechanical, electric and plumbing $(16.8 \%)$, and material $(16.4 \%)$.

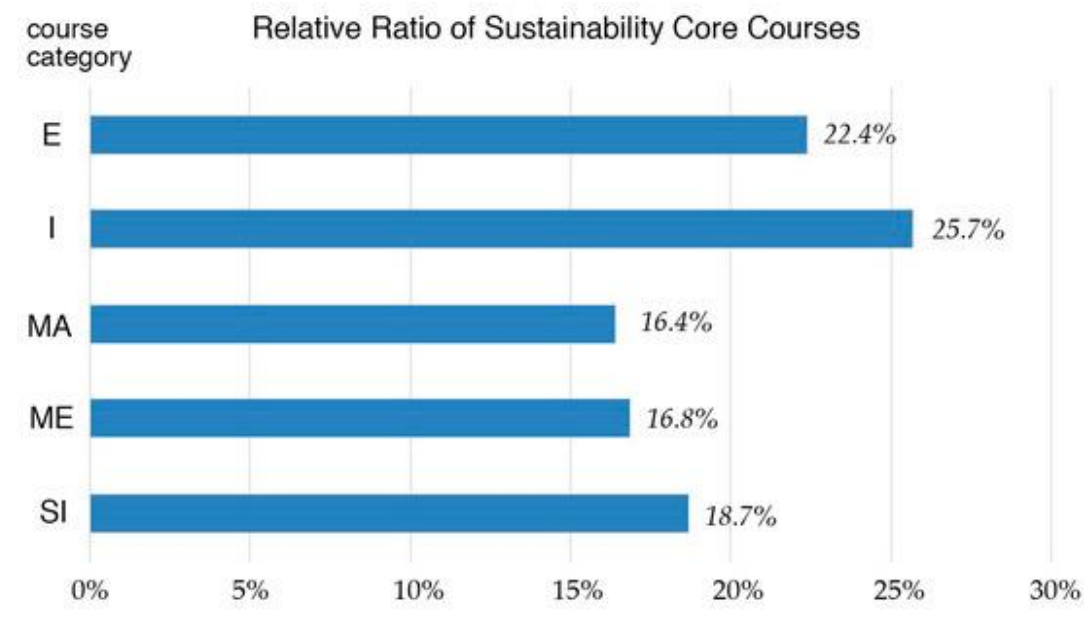

Fig. 3. Relative distribution ratio of the total credits assigned to the five sustainability core course categories (E, I, MA, ME and SI). The total of $100 \%$ in this graph correlates with $65.9 \%$ of all SPC credits assigned to sustainability-related courses.

The general learning goal of sustainable architectural education is to develop the students' ability to design and plan integrated architecture projects that meet sustainability criteria, rather than accumulate purely theoretical knowledge. Thus, a close integration and application of theory and practice can make a positive impact. One reason for this poor integration of theory courses with studios may be the KAAB accreditation system itself [18]. The main identified barriers are a clear separation of SPCs in understanding and ability-based learning goals, segregated assignments of these goals to sustainability core courses and studios, and the way in which the KAAB accreditation system enforces this separation.

\subsection{Method of training of specialists in the sphere of sustainable development on the example of the Nigerian University}

Let's consider in more detail a technique of training of specialists and structure of the curriculum of the Nigerian university in terms of sustainable development.

Currently, in the Nigerian architectural education inclusions of sustainability aspects are fragmented relying heavily upon individual efforts of lecturers that are familiar and inclined towards the subject matter. There is a need to review the existing curriculum to significantly include the worthy aspects of sustainability in the courses content and delivery mode.

There is a need of revision of the existing training programs by means of significant inclusion of courses according to the programs studying aspects of sustainable development.In Nigeria, environmental awareness is not a prominent feature of education programmes in institutions of primary, secondary or higher learning. However, its presence helps to mainstream environmental education programmes into schools as a regular part of 
the curriculum, increase public environmental awareness and demonstrates a commitment to environmental protection. Environmental education can be integrated into existing disciplines or it can be taught as a subject as early as primary school, as well as in adult education programmes this will foster the environmental responsibilities amongst students.

A complete integration of sustainable development across the curriculum, i.e. in all modules and parts of relevant subjects and activities through all phases is needed in encouraging sustainable practices in civil engineering fields (Shafii, 2007). The fundamental idea is that when sustainability is to become essential for all activities within society and all sectors of economy, it cannot remain as an isolated field of expertise but must form mindset for everyone[19, 20].

\section{Results}

The analysis of the higher education in the sphere of sustainable development shows that there is a need of inclusion of the concept steady and practicians of design thinking at all levels, beginning from ideological (stability as conceptual and ethical justification of architecture), and at the methodological level (the principles and strategy for the solution of various subject matters) and, at last, practical level, by introduction of stability concerning programs for architectural education and to impart abilities to critically analyze process and to creatively find sustainable solutions which can be developed for creation of the environment[21].

The systematic policy which is concentrated on all three important components of an education system is important: accurately definite purposes, planning according to these purposes and assessment of programs for specification of the purposes.

The two-level programs implemented at the universities consisting of the system of architectural education and a subsystem of steady architectural design (consisting of the steady theoretical and design training/practical courses and cross-disciplinary courses connected with education in the field of sustainable development in the architectural training program) are presented in this article [22].It has to demand from students to work and analyze the real environmental problems connected with water and power systems in various scales or on the university or in society in general.

Professionally, the quality of service offered in a global economy by a business is directly impacted by professional education standards, which are delineated by a common agreement. As such, the accreditation systems in architectural education are a core issue in educational debates, as they set minimum requirements for the curriculum and the rigor with which this content is taught. However, there is concern about accrediting bodies' regulations not doing enough, and even becoming an obstacle that confines the designer's imagination and stratagem when envisioning sustainable environments [23].

In order tointegrate stability and to use both creative and technical skillsbetter, it is necessary to reconsider education by introduction of creative and steady design methods. At many universities of the countries of the world,the integration of sustainable development into the curriculum are successfully implementedat various levels of the higher education programs.

\section{Discussion}

A complete education in sustainability is only possible when the three categories of sustainability-environmental, sociocultural and economic-are properly balanced. Architecture and urbanism are deeply related to the socioeconomic conditions of a particular time and place. With respect to the KAAB's incipient task of regional 
accreditation in the Asia-Pacific region, special attention to specific local and regional peculiarities is necessary. Therefore, the sustainability SPCs should undergo major revision, in order to create a meaningful international accrediting service that upholds substantial equivalency[24].

The correct inclusion of stability in the training program will have a number of important advantages. Among them it will lead to improvement of quality and relevance of education for all enlisted students. It will better prepare domestic students for full work of the house and abroad. And it will strengthen offers on involvement of foreign students in the competitive international market of education.

To increase the number of students and educational institutions, the public financing of the higher education and establishment supporting researches in the field has to pay more attention to questions and problems of stability and to respectively distribute funds. Head department at the universities could help with informing and training of the key faces making decisions in the government and departments on this major role and responsibility of the higher education in the 21 st century.

The higher education faces the growing expenses, problems with financing and interruptions in a type of open online courses. At all this, the emphasis on stability can provide a source of hope and opportunities for institutional changes[25].

\section{Conclusion}

In a present world situation, when quantity of resources which are necessary for modern life, for example, oil for energy production, are vital. Architects of the future have to be able to define the future through understanding of how society in the past learned to live within the limited resources available to them. (Vale and Vale, 2009). The higher architectural and construction education has to play an active role in assistance of increase in ecological literacy by means of introduction eco-friendly and the energy efficient construction materials in the projects. There is a real need to reorient architectural and construction education in the direction of sustainable development to have a clear idea that their main role in interaction with other spheres.

In compliance with "The national strategy of education for sustainable development of Russia" and "The action plan by training for sustainable development", in which preparation of the working group under the direction of the member correspondent of RAN of N.S. Kasimov was engaged, it is possible to formulate stages of introduction of stability in education in the territory of the Russian Federation:

- formation of political mechanisms, regulatory framework and organizational bases of implementation of the strategy focused on education in the sphere of sustainable development;

- training of specialists in the sphere of sustainable development;

- assessment of relevance of curricula and programs of the higher education into account requirements of sustainable development;

- development of educational means and methodical manual, activization of research and development on a subject of sustainable development;

- development of additional education;

- involvement of mass media and impact on pupils and also greening of society.

The steady architectural program of increase in education will work to overcome a gap between requirements of modern society and competence of the professionals capable to solve objectives for improvement of quality of education and its relevance in the future.

\section{References}


1. S. Sterling, Achieving a closer relationship between education and SD 8(2), 89-112 (2014)

2. T. Schrand, Sustainability 6(4), 207-210 (2013)

3. Leading Profound Change: A Resource for Presidents and Chancellors of the ACUPCC (Presidents Climate Commitment, American College \& University, 2009)

4. D. Orr, Earth in Mind: On Education, Environment and the Human Prospect (Island Press, 2004)

5. W. Attoe, R. Mugerauer, Excellent studio Teaching in Architecture 16, 41-50 (1991)

6. Framework for Curriculum Development (EDUCATE, 2012)

7. N. Kishnani, Greening Asia: Emerging Principles for Sustainable Architecture (2012)

8. S. Hamiti, H. Wydler, Sustainability 6, 3291-3300 (2014)

9. S.P. Alvarez, K. Lee, J. Park, S.Y. Rieh, Sustainability 8 (2016)

10. J. Wright, Introducing Sustainability into the Architecture Curriculum in the United States 4, 100-105 (2003)

11. K. Warburton, Deep Learning and Education for Sustainability 4, 44-56 (2003)

12. A.Z. Khan, H. Vandevyvere, K. Allacker, Design for the Ecological Age: Rethinking the Role of Sustainability in Architectural Education, 175-185 (2013)

13. S. Altomonte, P. Rutherford, R. Wilson, Mapping the Way Forward: Education for Sustainability in Architecture and Urban Design 21, 143-154 (2014)

14. Z. Shari, M.F.Z. Jaafar, Towards a More Sustainable Architectural Education in Malaysia 1, 57-64 (2006)

15. S. Trachte, A. De Herde, M. López de Asiaín, C.E. Burgos, S. Altomonte, A. Gobson, Sustainable Architectural Education (White Paper, 2012)

16. Y. Jabareen, A New Conceptual Framework for Sustainable Development 10, 179-192 (2008)

17. P.R. Berke, J. Kartez, Sustainable Development as a Guide to Community Land Use Policy (1995)

18. P. Healey, T. Shaw, Planners, plans and sustainable development, 769-776 (1993)

19. D.H. Meadows, D.L. Meadows, J. Beyond Randers, Confronting global collapse, envisioning a sustainable future (1992)

20. J. Robinson, J. Tinker, Reconciling ecological, economic and social imperatives: A new conceptual framework, 71-94 (1997)

21. P. Scruggs, Guidelines for State Level Sustainable Development (Center for Policy Alternatives, Ottawa, 1993)

22. KAAB Conditions \& Procedures for Professional Degree programs in Architecture, 2013 Edition (Korea Architectural Accrediting Board, 2013)

23. A. Abreu, Harnessing New Scientific Capacity. In Rio +20 Science for sustainable development (2012)

24. O.B. Adegun, Shelter and the future African city. The Built and Human Environment Review 4(2), 33-40 (2011)

25. What is Agenda 21 (ICLEIUSA, 2012) 